\title{
Spiritual pain from persistent chemotherapy-induced peripheral neuropathy in colon cancer patients in Japan
}

\author{
Ayumi Kyota ${ }^{1}$, Kiyoko Kanda ${ }^{2}$, Masako Honda ${ }^{3}$, Kenji Nakazawa ${ }^{4}$ and Keiko Fujimoto ${ }^{2 *}$
}

*Correspondence: kfujimoto@gunma-u.ac.jp

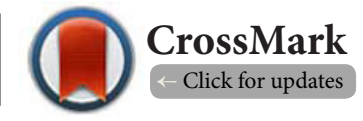

'Palliative Care Clinic IPPO, 790 Kyome-machi, Takasaki-shi, Gunma, Japan.

${ }^{2}$ Graduate School of Health Sciences, Gunma University, 3-39-22 Showa-machi, Maebashi-shi, Gunma, Japan.

${ }^{3}$ National Hospital Organization Shibukawa Medical Center, 383 Shiroi, Shibukawa-shi, Gunma, Japan.

${ }^{4}$ Saitama Sekishinkai Hospital, 1-33 Unoki, Sayama-shi, Saitama, Japan.

\begin{abstract}
The objective of this study was to analyze the spiritual pain from persistent chemotherapy-induced peripheral neuropathy (PCIPN) in colon cancer patients receiving long-term oxaliplatin therapy. The subjects were 20 colon cancer patients who underwent therapeutic intervention including oxaliplatin with a total dose of at least $850 \mathrm{mg} / \mathrm{m}^{2}$ at the outpatient department of the hospital. Data were collected via a semi-structured interview method and analyzed with method of content analysis. Spiritual pain from PCIPN was expressed by a total of 6 subjects and formed 2 categories, "Losing sight of my values because of functional impairment from PCIPN" and "Threatening the value of my existence in the family owing to PCIPN." The present study revealed that spiritual pain from PCIPN existed not only in the patients' selfcontained distress, but also in the distress related to their family relationships.
\end{abstract}

Keywords: Spiritual pain, chemotherapy, neuropathy, colon cancer, oxaliplatin

\section{Introduction}

Chemotherapy including oxaliplatin has been established as the first-line therapy for unresectable advanced or recurrent colon cancer and can be expected to prolong survival.

However, an adverse event of this therapy, peripheral neuropathy, worsens patients' quality of life (QOL), and makes difficult continuing of treatment.

Acute peripheral neuropathy that appears immediately after administration of oxaliplatin is reversible and can be handled by methods such as avoiding cold stimulation. Nevertheless, persistent chemotherapy-induced peripheral neuropathy (PCIPN) is cumulative and dose-dependent, and no effective method of dealing with it has been established; the only choices are to discontinue the treatment or reduce the dose [1]. The period from discontinuation of oxaliplatin until the disappearance of symptoms was up to 13 months in $78 \%$ of cases [2]. Thus, even treatment has been stopped, the patient must endure symptoms for a considerable period.

For patients, PCIPN is an adverse effect unlike anything previously experienced. It is anticipated not only to affect daily life but also to lead to a sense of isolation from others' lack of understanding and a strong sense of anxiety about how long it will continue.

Previous studies cleared that patients described emotional distress, depression, and loss of purpose as a result of having to give up enjoyable activities due to chemotherapy-induced peripheral neuropathy $[\mathbf{3}, \mathbf{4}]$. In Japan, it was clarified issues such as the appearance of symptoms, impediments to activities of daily living (ADL), and restrictions on social life $[5,6]$.

Only few reports have focused on spiritual pain (SP). PCIPN not only decreases QOL, but it may also cause deep distress, including SP. SP composes total pain with other components, such as physical, psychological and social distress. In addition, SP has the particularity; great deal of physical, psychological and social distress could be cause of SP. SP caused by PCIPN reduces meaning of chemotherapy, even though it has a certain degree of effect on the patient. Therefore we need to more focus on SP.

Nurses have the role of understanding and assessing patients' suffering holistically and providing support. Qualitative studies of the levels of patient suffering and distress are therefore of significance.

This study elucidated the spiritual pain from persistent 
chemotherapy-induced peripheral neuropathy in colon cancer patients receiving long-term oxaliplatin therapy.

\section{Patients and Methods Operational definitions of key terms}

Persistent chemotherapy-induced peripheral neuropathy: Progressive sensory disturbance, hypoesthesia, and disorders such as loss of proprioception continuing for at least 14 days. Symptoms include sensory functional disorders such as difficulty writing, walking, and drinking due to numbness of the hands, feet, and other regions.

Spiritual pain: Suffering produced by facing the potential loss of one's existence and meaning of live and distress, including feelings of meaninglessness, worthlessness, emptiness, isolation, and alienation in life that occur from the loss of a future in people facing death, loss of relationships with others, and loss of autonomy [7]. In this study, we define a patient with spiritual pain as one who can no longer see the meaning of life, loses sight of the implication of continuing the treatment, and suffers from loss of social role and relationships with others, reduction of self-efficacy, loss of hope for the future and increasing fear of death, due to persistent chemotherapy-induced peripheral neuropathy.

\section{Research subjects}

The subjects were 20 colon cancer patients who received FOLFOX chemotherapy or XELOX chemotherapy including oxaliplatin at least 10 times with a total dose of at least $850 \mathrm{mg} / \mathrm{m}^{2}$ at the outpatient department of Hospital A and who consented to being involved in the study. The subjects were not diagnosed with other diseases caused of PCIPN.

\section{Data collection}

Attending physicians or a head nurse of the outpatient chemotherapy department introduced a researcher to candidates of the subjects. When the subjects consented to participate after were explained the study, we decided a day of interview.

Semi-structured interviews on suffering due to PCIPN were conducted using an interview guide. The interview included questions on (1) symptoms of PCIPN, (2) effects of these symptoms on daily life, and (3) suffering due to symptoms and changes in daily life.

The interviews lasted about 30 to 60 minutes and, in consideration of the patients' conditions, the time of the interviews was set so that it did not interfere with medical appointments or nursing care. The interviews were conducted in a private room in the survey institution in order to protect privacy.

The interviews were recorded with an IC recorder after obtaining the subjects' consent.

Transcripts were generated from the recorded data and used in the analysis. When consent was obtained, we also used information on subject background collected from medical records.

\section{Analytical methods}

The statements on suffering obtained in the interviews were clas- sified based on the concept of total pain. In this study, subject statements expressing SP were qualitatively and inductively analyzed using Berelson's content analysis method [8]. This method is suitable for a procedure for verbal communications in a systematic and objective fashion, and analytical confidence is guaranteed by Scott's agreement rates.

Content that express distress related to suffering produced by facing the potential loss of the meaning of living and the value of existence was extracted from the transcripts and used as recorded units. Recorded units with the same meaning were gathered and coded, and they were categorized and subcategorized in accordance with the similarity of content.

All stages of this study were supervised by researchers wellversed and experienced in qualitative research methods in the field of cancer nursing. Two people with experience in qualitative research related to cancer nursing were asked to perform the analysis, and Scott's agreement rates between categories and subcategories were calculated. In this study, the agreement rate was $83.2 \%$.

\section{Ethical considerations}

Approval was received from the medical ethics committee of the survey institution, and the study was conducted based on ethical standards. We explained to the subjects orally and in writing. Participation consented voluntary.

\section{Results \\ Subjects' characteristics}

Twenty-three patients were introduced by physicians or head nurses, and 22 patients consented to participate after the study had been explained. However, 2 patients could not complete the interview because of the deterioration of their conditions. Finally, 20 patients were included as participants. All of the patients consented to the use of information from their medical records and the recording of their interview. Data was collected from March 2011 to March 2012.

The 6 persons in total 20 subjects showed SP. The subjects' characteristics are shown in Table 1. The subjects were 2 men and 4 women, with a mean age of $58.7 \pm 13.3$ years.

The subjects' performance status (PS) was Grade 1 in all 6 subjects. Based on the Common Terminology Criteria for Adverse Events (CTCAE; v. 4.0) as a marker for the degree of peripheral neuropathy, 3 subjects were Grade 1, 3 subjects were Grade 2 . We analyzed the statistical difference using a non-parametric test based on age, number of treatments, and the total dose between the shown SP group and the not shown group, but no significant difference was found.

The two Grade 3 subjects did not express SP. One participant said, "I am frustrated that I cannot keep working in my home garden, so I leave it to my son." However, he did not talk about SP. On the other hand, two Grade 1 subjects who were housewives expressed SP, explaining, "even though my family helps me, I am distressed that I no longer have a role to play in my family. And I am in anguish because it will only get worse until 
Table 1. Subject's characteristics.

\begin{tabular}{|c|c|c|c|}
\hline & Shown SP & $\begin{array}{l}\text { Not } \\
\text { Shown SP }\end{array}$ & $\begin{array}{l}\text { Total } \\
(\mathbf{n}=20)\end{array}$ \\
\hline \multicolumn{4}{|l|}{ Sex } \\
\hline Male & 2 & 9 & 11 \\
\hline Female & 4 & 5 & 9 \\
\hline \multicolumn{4}{|l|}{ Occupation } \\
\hline Yes & 1 & 4 & 5 \\
\hline No & 5 & 10 & 15 \\
\hline -- full-time housewife & 3 & 5 & 8 \\
\hline \multicolumn{4}{|l|}{ Living-together Family } \\
\hline Yes & 6 & 12 & 18 \\
\hline No & 0 & 2 & 2 \\
\hline \multicolumn{4}{|l|}{ Age (years) } \\
\hline Average & 58.7 & 66.7 & 64.3 \\
\hline SD & 13.3 & 8.5 & 10.8 \\
\hline \multicolumn{4}{|l|}{ Number of Therapy Times } \\
\hline Average & 17.7 & 19.3 & 18.8 \\
\hline SD & 6.6 & 8.9 & 8.4 \\
\hline \multicolumn{4}{|l|}{ Total Dose $\left(\mathrm{mg} / \mathrm{m}^{2}\right)$} \\
\hline Average & 1839.2 & 1729.3 & 1762.3 \\
\hline SD & 1003.0 & 747.4 & 883.9 \\
\hline \multicolumn{4}{|l|}{ PS } \\
\hline Grade 1 & 6 & 12 & 18 \\
\hline 2 & - & 2 & 2 \\
\hline \multicolumn{4}{|l|}{ CTCAE v4.0 } \\
\hline Grade 1 & 3 & 6 & 9 \\
\hline 2 & 3 & 6 & 9 \\
\hline 3 & - & 2 & 2 \\
\hline
\end{tabular}

I stop chemotherapy."

\section{Spiritual pain from persistent chemotherapy- induced peripheral neuropathy}

The 20 subjects expressed a total of 336 recorded units of pain, of which $40.8 \%$ was physical pain, $32.4 \%$ was social pain, $20.8 \%$ was emotional pain, and $6.0 \%$ was SP. From the 20 recorded units, 16 codes, 4 subcategories, and 2 categories were formed (Table 2). In the following, the codes are shown in italics, the subcategories are shown in <angle brackets>, and the categories are shown in bold text.

\section{Losing sight of my value because of functional impairment from PCIPN}

This category was typified by the code Control of cancer with anticancer drugs is meaningless if my legs are disabled from numbness, and it was formed from the subcategories of <losing the meaning of treatment that offers no hope of a cure because of the terrible PCIPN> and <suffering from PCIPN due to no longer being able to do routinely things. $>$ Here, since treatment is done with the purpose of prolonging life or ameliorating symptoms, with no prospect of a complete cure, the characteristic factor is the loss of the value of existence as a result of PCIPN.

\section{Threatening the value of my existence in the family with PCIPN}

This category was formed from the subcategories of $<$ Questioning one's value in their family with respect to continuation of treatment and resulting distress $>$ and $<$ Losing the meaning of living without being able to fulfill a role within the family as a result of PCIPN. > Here, as shown by the code, I understand that family members help out of kindness, but I have a feeling of helplessness as if being told I was useless, the characteristic factor is the possibility that the existence of family is not necessarily a source of positive support for the subject.

\section{Discussion}

The present study demonstrated that even patients who connect outpatient chemotherapy with hope may feel distress equivalent to the wavering of the value of their own existence as a result of PCIPN. This result is similar to the findings of an attitude survey of patients receiving outpatient chemotherapy [9], and questions on the meaning of life and the meaning of therapy in which the patient "feels chained to therapy and wonders what it is for" [10].

Additionally, the presence or absence of expressions of SP in the present study was shown to be unrelated to the CTCAE or PS, which describe the level of restriction in daily life from PCIPN. The possibility was suggested that even patients who are "superficially doing well" while receiving therapy experience the deep distress of SP based on what it means to be human.

The two Grade 1subjects who expressed SP were concerned with the loss of their role as a housewife. In general, housewives do not retire. Consequently, they may suffer more than others when they have to leave their housework to their family members even though they are "superficially doing well." In addition, it is clear that they may have deep SP because of concerns regarding their further deterioration. While all patients who receive chemotherapy hope to survive, some may suffer SP, which is a loss of meaning for their life, from receiving this therapy. Thus, patients may face a dilemma as to whether they should stop chemotherapy.

The number of patients receiving chemotherapy on an outpatient basis is rising each year, because of advances in therapeutic drugs, policies to constrain the high cost of medical care, and diversifying patient needs. Outpatient nurses, in circumstances of limited time and human resources, prioritize the safe implementation of chemotherapy, and they must carry out cumbersome tasks including vascular access, double-checking of drugs, and observation of side effects. Currently it is practically impossible to spend the time to listen carefully to all patients receiving chemotherapy about the distress they experience. For that purpose, effective screening of patients who do and do not require active intervention for SP is necessary, for which assessment tools need to be developed. 
Table 2. Spiritual Pain from Persistent Chemotherapy-Induced Peripheral Neuropathy.

Units; Record Units (\%) $\mathbf{n}=\mathbf{2 0}$

\begin{tabular}{|c|c|c|}
\hline Categories & Subcategories & Codes \\
\hline \multirow[t]{2}{*}{$\begin{array}{l}\text { Losing sight of my value } \\
\text { because of functional } \\
\text { impairment from PCIPN } \\
9 ; 45.0 \%\end{array}$} & $\begin{array}{l}\text { Losing the meaning of } \\
\text { treatment that offers no hope } \\
\text { of a cure because of the terrible } \\
\text { PCIPN } \\
5 ; 25.0 \%\end{array}$ & $\begin{array}{l}\text { "Control of cancer with anticancer drugs is meaningless if my legs are } \\
\text { disabled due to numbness". } \\
\text { "Life with numbness is difficult, and I wonder if it would be better to choose } \\
\text { not to receive treatment". } \\
\text { "I wonder whether there is any meaning behind enduring this numbness } \\
\text { resulting from treatment when there is no hope of a complete cure, and this } \\
\text { causes distress". } \\
\text { "I spend much of my time resting quietly because of numbness and } \\
\text { thinking about my future, which is distressing". } \\
\text { "Even though I will not recover from my disease, I would at least like to get } \\
\text { rid of this numbness so that I can do the things I want to do". }\end{array}$ \\
\hline & $\begin{array}{l}\text { Suffering from PCIPN due } \\
\text { to no longer being able to do } \\
\text { routinely things } 4 ; 20.0 \%\end{array}$ & $\begin{array}{l}\text { "I have been robbed of my work and hobbies by this numbness, and the } \\
\text { road in front of me is dark". } \\
\text { "I have a sense of helplessness in being unable to do anything by myself as a } \\
\text { result of this numbness". } \\
\text { "I think it will be the end when I can no longer walk because of this } \\
\text { numbness". } \\
\text { "I am miserable at not being able to do things I used to do routinely } \\
\text { because of numbness". }\end{array}$ \\
\hline \multirow[b]{2}{*}{$\begin{array}{l}\text { Threatening the value of my } \\
\text { existence in the family with } \\
\text { PCIPN 11;55.0\% }\end{array}$} & $\begin{array}{l}\text { Questioning one's value in } \\
\text { the family with respect to } \\
\text { continuation of treatment and } \\
\text { resulting distress } 5 ; 25.0 \%\end{array}$ & $\begin{array}{l}\text { "If I am of no use as a member of the family, there is no value in living as a } \\
\text { financial burden on my son and I would like to quit treatment". } \\
\text { "I don't feel like myself at all, since I am unable to go anywhere without } \\
\text { help from others. So, I am thinking about quitting the treatment". } \\
\text { "Family members tell me they want me to live a long time, and so I put up } \\
\text { with the treatment even though the numbness is considerable". }\end{array}$ \\
\hline & $\begin{array}{l}\text { Losing the meaning of living } \\
\text { without being able to fulfill } \\
\text { a role within the family as a } \\
\text { result of PCIPN } 6 ; 30.0 \%\end{array}$ & $\begin{array}{l}\text { "I feel like I am going to lose my meaning in life as a homemaker since I can } \\
\text { no longer do housework because of increased numbness". } \\
\text { "I understand that family members help out of kindness, but I have a } \\
\text { feeling of helplessness as if being told that I was useless". } \\
\text { "I become depressed at not being able to fulfill my role as a wife when } \\
\text { guests visit because of hand numbness". } \\
\text { "I feel like I am going to lose my meaning in life since I am not a useful } \\
\text { member of the family because of increased numbness". }\end{array}$ \\
\hline
\end{tabular}

The category of "Threatening the value of my existence in the family with PCIPN" indicates that a great deal of social distress can lead to SP. The present study revealed that SP from PCIPN exists not only in terms of the patients' distress, but also in the distress related to their family relationships. The existence of family can be a source of pressure on patients in Japan, and patients may experience distress in wondering whether their worth is equal to the burden it places on the family, seeing themselves as meaningless if they are unable to do anything for their family. Feelings of helplessness and loss of self-worth in patients may cause them to feel alienated from their family, leading to a disruption of the balance within the family and thus affecting the entire system.

The outpatient department nurses need to assess how patient PCIPN affects not only the individual but also the entire family. Moreover, support is needed that can help patients recognize their role in the family and discover new worth in their existence by providing positive feedback on things that they can do even with PCIPN and on remaining functions.

\section{Limitations of the study}

Spiritual pain is thought to strongly impact judgments of disease stage and treatment effect, and there are limitations to the generalization of the present results. It is therefore necessary to develop tools for assessing not only the physical severity, but also the psychological and spiritual influence of peripheral neuropathy.

\section{Competing interests}

The authors declare that they have no competing interests.

\section{Authors' contributions}

AK: Writing and research for the references

$\mathrm{AK}, \mathrm{KF}$ and $\mathrm{MH}$ : Analysis of data

KN: Data collection

KK: Final approval of the version submitted.

\section{Acknowledgement and funding}

We would like to thank all the patients who participated. 
The present study was part of a study conducted with support from a Grant-in-Aid for Scientific Research (B) (20390500). This study was presented at the $27^{\text {th }}$ Annual Conference of the Japanese Society of Cancer Nursing.

\section{Publication history}

Editors: Paul J. Higgins, Albany Medical College, USA. Tao Zhu, University of Science and Technology, China.

Received: 23 September 2016 Revised: 09 November 2016

Accepted: 24 November 2016 Published: 01 December 2016

\section{References}

1. Tournigand C, Cervantes A, Figer A, Lledo G, Flesch M, Buyse M, Mineur L, Carola E, Etienne PL, Rivera F, Chirivella I, Perez-Staub N, Louvet C, Andre T, Tabah-Fisch I and de Gramont A. OPTIMOX1: a randomized study of FOLFOX4 or FOLFOX7 with oxaliplatin in a stop-and-Go fashion in advanced colorectal cancer--a GERCOR study. J Clin Oncol. 2006; 24:394400. | Article | PubMed

2. Cassidy J and Misset JL. Oxaliplatin-related side effects: characteristics and management. Semin Oncol. 2002; 29:11-20. | Article | PubMed

3. Tofthagen C. Patient perceptions associated with chemotherapy-induced peripheral neuropathy. Clin J Oncol Nurs. 2010; 14:E22-8. | Article | PubMed

4. Bakitas MA. Background noise: the experience of chemotherapy-induced peripheral neuropathy. Nurs Res. 2007; 56:323-31. | Article | PubMed

5. Kashihara A, Nakayama T, Ikeshita M and Murakami K. Through conducting an interview survey the neurologic symptoms of the ELPLAT are considered. Med J Onomichi Munic Hosp. 2008; 24:13-7.

6. Takei A, Sheyama R, Ishida J and Kanda K. Difficulties and coping behavior in a life of the cancer patient who experienced the oxaliplatininduced peripheral neuropathy. Kitakanto Med J. 2011; 61:145-52.

7. Murata H. Spiritual pain and its care in patients with terminal cancer: construction of a conceptual framework by philosophical approach. Palliat Support Care. 2003; 1:15-21. | PubMed

8. Berelson B. Content Analysis in communication research. Free Press, Michigan. 1952.

9. Mukaigawa $Y$, Kobayashi $K$, and Kinoshita $M$. The nurse's role to a total pain of cancer patient; Survey of the cancer patient who receives foreign chemotherapy. Med J Hiroshima Pref Hosp. 2009; 41:73-8.

10. Naka H, Ouishi F and Ounishi K. The comparison between nurses' and patients' recognition relating to outpatient's distress and difficulty in receiving chemotherapy. Mie Nursing Journal. 2007; 9:41-54.

\section{Citation:}

Kyota A, Kanda K, Honda M, Nakazawa K and Fujimoto K. Spiritual pain from persistent chemotherapyinduced peripheral neuropathy in colon cancer patients in Japan. J Cancer Ther Res. 2016; 5:9. http://dx.doi.org/10.7243/2049-7962-5-9 